Is Venus Clocd-covered?-Mr. Evershed has taken many photographs of the spectrum of Venus in recent years, for the purpose (inter alia) of endeavouring to detect the Einstein shift, and of testing his own hypothesis that the earth has an effect on the atmospheric circulation of the sun. In the course of this work he found, to his surprise, that a much longer exposure-time was needed than was the case in fhotographing the spectrum of a cumulus cloud on which the sun was shining (Monthly Notices R.A.S., November). Mr. Evershed expected the time to be shorter, for the intensity of sunlight on Venus is $1 \cdot(92$ times as great as on the earth. Allowing for the alsorption of Venus's atmosphere, he concludes that if Venus were rovered with clouds similar to our cumulus clouds, the exposure-time would be less on the former than on the latter in the ratio of $I$ to $I \cdot 3$, whereas the contrary is the case. He concludes that the atmo. sphere of Venus is not cloud-laden, but that its lower strata contain much dust in suspension, veiling the surface features. This conclusion is similar to that reached by Prof. Lowell from his observations at Flagstaff.

Mr. Evershed thinks that the values of the colourindices assigned by Prof. H. N. Russell to the sun and Venus $(+0.70 \mathrm{~m}$. and $\div 0.78 \mathrm{~m}$.) are mutually inconsistent, since they imply that no selective absorption takes place in Venus's atmosphere. Mr. Fvershed finds evidence of decided selective absorption in the violet, as compared with his cloud spectra.

\section{PROFESSIONAL METEOROLOGY.}

SIX parts of the new Professional Notes of the 5 Meteorological Office have now been issued. The first ${ }^{2}$ deals with the relation between cloud and wind direction at $\mathrm{Richmond}$, and gives tables for each month for Ioh., I $6 \mathrm{~h}$., and $22 \mathrm{~h}$. for fifteen years, showing the number of times each cloud amount was associated with each wind direction or with calms; it would perhaps have been clearer if percentage values had been given. Several important points come out, such as the well-known tendency of cloud to disperse at night, but it is also shown that this tendency is not the same for all winds or for all seasons. Cloud forecasting became important during the war, and wiil in future be of wide application; it is to be hoped, therefore, that Lieut. (now Capt.) Brunt will fulfil his intention of continuing this research. Tables also give values for Greenwich for January and July, and various differences from Richmond are apparent; Richmond had only 59 calms in 180 months, whi?e Greenwich had $5^{\circ}$ in 20 months, which indicates, perhaps, a difference in estimating light winds. Greenwich had more south-west and fewer south and north-west winds than Richmond, due probably to local exposure.

It would be more satisfactory to compare cloud amount with wind at cloud-level or with sradient direction, for Mr. Newnham's paper ${ }^{2}$ on a night valler. wind shows that surface winds may he shallow and more or less unrelated to upper-air phenomena. Cold air flows down valleys at night in radiation weather. and if, at so onen a station as Benson, the wind at night sometimes blows "very steadily from east-bysouth to east-south-east resardless of what the direition had been during the previous day." the need for raution in dealing with surface winds is obvinus. But in the case of forg it is the surface wind that is of

1 "On the Inter-relation of Wind Direction ansl Clund Amonnt at Richmont?" Pv Lieut. David Brunt. (Metenrological Offi-e, To18.) Price $3 d$. "Notes on Fxamples of Katabitic. Wind in the Valley of the Upper Thames at the Aersloginal (Jisurvatory of the Metersolngical Office at Penson. Oxon." By E. V. Newnham. (Meteorolugical Ofice, ror8.)
Price jil. NO. 2625 , VOL. IO4] importance, as appears in Mr. Brooks's paper' on the fog in London on January 31, 1918, when the incidence of the fog seems to have been influenced by "shallow streams of cold air flowing down the sides of hills." The isobaric maps in this paper show $a$ bend in the isobars over the Thames estuary which $\mathrm{Mr}$. Brooks thinks is real, but possibly exagserated "by slight inaccuracies in some of the barnmeter readings." Those who draw isobars know how peculiar are some of the readings, and would welcome a future Professional Note on these neculiaritics.

$A$ vast amount of information was obtained during the war on upper-air temperatures and winds, and it would be a real loss to meteorology if this were un. used or lost. Lieut. Stacey and Capt. Chapman are therefore to be congratulated on having made use of some of these records. Lieut. Stacey ${ }^{+}$deals with upper-air temperatures at Martlesham Heath from February, 1917, to January, 1918, and sets nut the information clearly on the whole, though several mis. prints are noticeable. Unfortunatcly, "no information is to hand of the type and exposure of the instruments used," which is to be regretted, especially as one wo:ld suppose such information could have been obtained; as a matter of fact, the thermometers were exposed on the wing-struts of the aeroplanes, but the tvpe of thermometer varied from time to time, and therefore the early records are probably not strictly comparable with the late ones; but these facts are not recorded in the paper. It is very desirable that all details of meteorological war-work should be collected before it is too late to obtain them.

Capt. Chapman ${ }^{3}$ reviews formulie connectirg in crease of wind velocity with height. Many of the early ones were linear, but linear formula are un. likely, and were probably only intended as working guides until more observations were available. From a consideration of many observations, including roo in north-eastern France, the author deduces the formula $\mathrm{V}=a \log \mathrm{H}+b$ (where $\mathrm{V}$ is the wind velocity. $\mathrm{H}$ the height, and $a$ and $b$ are constants), which fits most of the observations below the height at which the mean gradient velocity is reached. The whole paper deserves careful studv. In another publication ${ }^{\circ} \mathrm{Capt}$. Chanman discusses the normal curve of errors in connection with what meteorological observations should be classified as unusual or excentional.

Meteorology has advanced rapidly in recent ycars, and these nublications, and others. show that the idvance in this countrv is due largelv to the Meteorolocical Office, and it is to be honed that its future activities may not be hamnered by the proverbially unscientific attitude of Government Departments.

\section{STEAM BOILERS AND FCONOMISERS.}

$A S$ chief engineer of the Manchester Steam Users' Association Mr. C. E. Stromeyer prepares a vearly memorandum. The memorandum for the year in 8-ig deals. with fuel economy and with economiser and furnace collapses. Some industries require much power and little steam for heating and boiling: others much steam and little power. If two such industries could combine, the cost of I h.p. could he reduced from, sav, $2 \mathrm{lb}$. of coal to $\frac{2}{3}$ ib. If, for instance, a spinning mill consumes 20 tons of roal 3 "Incidence of Fog in Inndon on January 31 , $1915 . "$ By C. E. P. Brooks. (Meteorological Office, 1918.) Price $3^{\prime \prime}$.

+ "Upper-Air Temperatures at Martlesham Heath. Februarv. January, 1918." By Lieut. W. F. Stacey. (Meteorolog cal Office, 1919.) Price is.

Price "The Variation of Wind Velocity with Height." By Capt. F. H Chapman. (Meteorological iffice.

6 "On the Use of the Normal Curve of Errors in Classifying Observations in Metcorolozy." By Ca! t. F. H. Chapman. (Meteorological Office, igrg. Price $6 d$. 